\title{
Silicon-Mediated Priming Induces Acclimation to Mild Water-Deficit Stress by Altering Physio-Biochemical Attributes in Wheat Plants
}

\section{OPEN ACCESS}

Edited by:

Youssef Rouphael,

University of Naples Federico II, Italy

Reviewed by:

Xiangnan $\mathrm{Li}$

Northeast Institute of Geography and Agroecology (CAS), China

Vasileios Fotopoulos,

Cyprus University of Technology,

Cyprus

*Correspondence:

Arruje Hameed

arrujetahirfsd@gmail.com; arrujeh@yahoo.com

Specialty section: This article was submitted to

Plant Abiotic Stress,

a section of the journal

Frontiers in Plant Science

Received: 03 November 2020 Accepted: 18 January 2021

Published: 19 February 2021

Citation:

Hameed A, Farooq T, Hameed A and Sheikh MA (2021)

Silicon-Mediated Priming Induces Acclimation to Mild Water-Deficit Stress by Altering Physio-Biochemical

Attributes in Wheat Plants.

Front. Plant Sci. 12:625541.

doi: 10.3389/fp/s.2021.625541

\section{Arruje Hameed ${ }^{1 *}$, Tahir Farooq ${ }^{2}$, Amjad Hameed ${ }^{3}$ and Munir Ahmad Sheikh ${ }^{4}$}

${ }^{1}$ Department of Biochemistry, Government College University Faisalabad, Faisalabad, Pakistan, ${ }^{2}$ Department of Applied Chemistry, Government College University Faisalabad, Faisalabad, Pakistan, ${ }^{3}$ Nuclear Institute for Agriculture and Biology (NIAB), Faisalabad, Pakistan, ${ }^{4}$ Institute of Molecular Biology and Biotechnology (IMBB), The University of Lahore, Lahore, Pakistan

Water-deficit stress negatively affects seed germination, seedling development, and plant growth by disrupting cellular and metabolic functions, reducing the productivity and yield of field crops. In this study, sodium silicate (SS) has been employed as a seed priming agent for acclimation to mild water-deficit stress by invoking priming memory in wheat plants. In pot experiments, the SS-primed (20, 40, and $60 \mathrm{mM}$ ) and non-primed control seeds were allowed to grow under normal and mild water-deficit conditions. Subsequently, known methods were followed for physiological and biochemical studies using flag leaves of 98-day mature wheat plants. The antioxidant and hydrolytic enzymes were upregulated, while proteins, reducing sugars, total sugars, and glycine betaine increased significantly in the flag leaves of wheat plants originated from SStreated seeds compared to the control under mild water-deficit stress. Significant decreases in the malondialdehyde (MDA) and proline contents suggested a controlled production of reactive oxygen species, which resulted in enhanced cell membrane stability. The SS priming induced a significant enhancement in yield, plant biomass, and 100-grain weight of wheat plants under water-deficit stress. The improvement in the yield parameters indicated the induction of Si-mediated stress acclimation in SSprimed seeds that elicited water-deficit tolerance until the maturity of plants, ensuring sustainable productivity of climate-smart plants.

Keywords: seed priming, sustainable productivity, water-deficit stress tolerance, wheat, silicon

\section{INTRODUCTION}

Around the world, sustainable agriculture is facing severe threats from ecotoxicological conditions, climate change, and environmental stresses that pose serious challenges to global food security. Plants growing in a dynamic environment are heavily influenced by the aforesaid stress factors and exhibit a significant reduction in growth, development, and final yield, although they try to counterbalance the negative impacts through certain adaptive mechanisms, such as changing the osmotic potential, plant structure, and growth pattern, boosting the antioxidant defense potential 
and regulating physiological and biochemical processes (Teh and Koh, 2016). Over the years, drought or water deficit has been recognized as the most brutal environmental stress that retards the growth and development of plants by having negative impacts on the physiological, biochemical, and morphological traits. It hampers the normal metabolic, antioxidant, and photosynthetic activation and nutrient movement in plants. The disrupted processes at the subcellular level impair the growth-promoting parameters and lead to reduced plant growth and biomass and to yield losses (Wang et al., 2018; Easwar Rao and Viswanatha Chaitanya, 2020). Wheat is a major staple food, and its seed germination, seedling growth, and plant development also experience the drought-induced negative impacts, which ultimately result in low yield (Amirjani and Mahdiyeh, 2013; Guo et al., 2017). Wheat plants experience negative changes in protein contents, antioxidant potential, and hormone composition at the vegetative and reproductive stages under drought. It also influences the chlorophyll content, cuticle thickness, and opening and closing of the stomata (Bano et al., 2012; Guan et al., 2015; Li et al., 2020). In fact, water limitations severely reduce the uptake and translocation of macro- and micronutrients, which affect leaf-water relations, photosynthesis, and chlorophyll fluorescence, resulting in reduced plant growth, early senescence, and low wheat productivity (Zlatev, 2009; Karim et al., 2012; Wang et al., 2017).

Seed germination is one of the major phases in the life of higher plants in which all well-regulated metabolic, biochemical, and physiological processes ensure the rapid and uniform emergence of seedlings and plant development. Priming is a seed pre-conditioning technique that modulates the biochemical and physiological processes for the acceleration of germination and alleviation of stress, and for higher crop yields. In fact, it programs the seeds for the tolerance of abiotic stresses by regulating metabolism, antioxidant enzymes, and protein synthesis and readjusting the underlying subcellular pathways (Wojtyla et al., 2016; Hameed et al., 2019). Over the last few decades, a range of physical, chemical, and biological treatments have been well explored for hydropriming, chemopriming, biopriming, and thermoprining for pre-germinative metabolic modulations in seeds in order to withstand abiotic and biotic stress conditions at germination, seedling growth, and plant development. Various natural and synthetic priming agents (inorganic salts, organic molecules, and natural metabolites) have been reported to boost the antioxidant potential as a stress-responsive strategy for the alleviation of drought-induced damages in germinating seeds (Aranega-Bou et al., 2014; Savvides et al., 2016; Singh et al., 2020). Various studies have reported the applications of salicylic acid, abscisic acid, jasmonic acid, hydrogen peroxide, ascorbic acid, sodium nitroprusside, sodium chloride, sodium glutamate, etc., as wheat seed priming agents to induce tolerance against drought and to mitigate the abovementioned negative impacts (Hameed and Iqbal, 2014; Bhardwaj et al., 2017; Habib et al., 2020).

Over the last few decades, several authors have reported the ability of silicon ( $\mathrm{Si}$ ) to induce tolerance against biotic and abiotic stresses, including salinity, high temperature, chilling, drought, etc. It accelerates seed germination and enhances plant growth and crop yield. It acts as a plant protectant and biostimulant under a range of stress conditions. It also improves the water status and water use efficiency of plants and reduces lipid peroxidation under drought stress (Hasanuzzaman et al., 2018; Liu et al., 2019). It could regulate osmolyte accumulation and readjust osmotic potential under water-deficit conditions. Si provision improved the yield of rice by increasing the mobilization of photoassimilates and amino acids from vegetative tissues to grain and nitrogen use efficiency. It redirected the primary metabolism by acting as a signaling factor under unstressed conditions (Pang et al., 2019; Mohanty et al., 2020).

Keeping the above facts in mind, this study was planned to employ $\mathrm{Si}$ as a wheat seed priming agent to induce acclimation to mild water-deficit stress until the maturity of plants.

\section{MATERIALS AND METHODS}

In this study, spring wheat (Triticum aestivum L. cv. AARI2011) seeds (100 g for each treatment) were primed with 20 , 40 , and $60 \mathrm{mM}$ sodium silicate (SS) solution, the Si donor, for $8 \mathrm{~h}$. Then, they were washed and dried at $26 \pm 2{ }^{\circ} \mathrm{C}$ under shade. On the other hand, some wheat seeds were soaked only in water to achieve hydro-primed seeds for comparative study. Pot experiments with a completely randomized design were conducted in three replicates (five pots per replicate with five seeds per pot) to investigate the effects of silicon-induced priming on mature wheat plants produced from SS-primed seeds under normal and mild water-deficit conditions. Each pot was filled with $1.4 \mathrm{~g} \mathrm{~cm}^{-3}$ sandy clay loam soil containing 22\% clay, 33\% silt, and $45 \%$ sand. Normal growth conditions were maintained by providing water at soil water-holding capacity. On parallel, the drought stress was induced by maintaining water at $50 \%$ soil water-holding capacity. Physiological and biochemical analyses were performed using flag leaf samples collected from 98day matured plants originated from SS-primed, hydro-primed, and non-primed control seeds grown under normal and mild drought conditions.

\section{Physiological Analyses}

A known conductometric method was employed for the measurement of cell membrane stability (CMS) (Blum and Ebercon, 1981). The samples were autoclaved for $24 \mathrm{~h}$ before and after conductivity reading from the control (C) and stressed (T) leaf samples.

$$
\text { CMS } \%=\left[\left(1-\left(T_{1} / T_{2}\right)\right) /\left(1-\left(C_{1} / C_{2}\right)\right)\right] \times 100
$$

where $T_{1}$ is the stress sample conductance before autoclaving, $T_{2}$ is the stress sample conductance after autoclaving, $C_{1}$ is the control sample conductance before autoclaving, and $C_{2}$ control sample conductance after autoclaving.

The water status parameters (turgor, osmotic, and water potential) were measured using the youngest leaf samples according to known procedures. The difference between the water potential $\left(\Psi_{w}\right)$ and osmotic potential $\left(\Psi_{s}\right)$ values provided the leaf turgor potential $\left(\Psi_{p}\right)$.

$$
\left(\Psi_{p}=\Psi_{w}-\Psi_{s}\right)
$$




\section{Biochemical Analyses \\ Biomolecules}

Total soluble proteins (TSPs) were estimated by the method of Bradford using bovine serum albumin (BSA) as the standard (Bradford, 1976). Reducing sugars were determined using a well-known dinitrosalicylic acid method (Miller, 1959) and the total sugar content estimated using the phenol sulfuric acid reagent method (Dubois et al., 1951). The reducing and total sugar contents were determined from a standard curve prepared by using glucose as the standard. Non-reducing sugars were calculated by subtracting the reducing sugars from the total sugars.

\section{Enzymatic and Non-enzymatic Antioxidants}

For the different biochemical analyses, leaf samples (0.5 g) were ground in specific extraction buffer and centrifuged at $15,000 \times g$ for $20 \mathrm{~min}$ at $4^{\circ} \mathrm{C}$ for different biomolecules and enzymes. Subsequently, the separated supernatant was employed for the below given biochemical analyses according to wellestablished methods. Spectroscopic analyses were performed using a spectrophotometer (Hitachi, U2800).

Specific extraction buffers were used to homogenize the leaf samples $(0.5 \mathrm{~g})$ as in a known procedure. The activity of superoxide dismutase (SOD) was assayed by measuring its ability to inhibit the photochemical reduction of nitroblue tetrazolium (NBT) following a known method (Giannopolitis and Ries, 1977). One unit of SOD activity was defined as the amount of enzyme which caused $50 \%$ inhibition of photochemical reduction of NBT. The activities of peroxidase (POD) and catalase (CAT) were also measured using a well-established method (Chance and Maehly, 1955). For POD activity, we noted an increase in the absorbance of the reaction solution at $470 \mathrm{~nm}$. In the case of CAT activity, we recorded a decrease in the absorbance of the reaction solution at $240 \mathrm{~nm}$. An absorbance variation of $0.01 \mathrm{U} / \mathrm{min}$ was taken as one unit of CAT and POD activities. Further, the activities of enzymes were expressed on seed weight basis.

The level of lipid peroxidation was measured in terms of malondialdehyde (MDA, a product of lipid peroxidation) content determined by a known method which involves thiobarbituric acid (TBA) reaction (Heath and Packer, 1968). An extinction coefficient of $155 \mathrm{mM}^{-1} \mathrm{~cm}^{-1}$ was used for the calculation of MDA content. The FolinCiocalteu reagent was employed according to a known micro-colorimetric method for the determination of the total phenolic content (TPC) (Ainsworth and Gillespie, 2007). A linear regression equation was used for the measurement of TPC after preparing the standard curve with different concentrations of gallic acid.

\section{Hydrolytic Enzymes}

Protease activity was determined by a known casein digestion assay (Drapeau, 1976). The absorbance of the filtrate was measured at $280 \mathrm{~nm}$. By this method, $1 \mathrm{U}$ is the amount of enzyme that releases acid-soluble fragments equivalent to $0.001 A_{280}$ per minute at $37^{\circ} \mathrm{C}$ and $\mathrm{pH} 7.8$. Enzyme activity was expressed on a protein basis. The $\alpha$-amylase activity was determined by following a reported method (Varavinit et al., 2002). Accordingly, maltose was used for the construction of the standard curve to measure enzyme activity.

\section{Osmolytes}

The known acid ninhydrin method was employed for the measurement of proline content at $520 \mathrm{~nm}$ and expressed as micrograms proline per gram fresh weight (FW) (Bates et al., 1973). A known spectroscopic method was adopted for the determination of glycine betaine (GB) (Grieve and Grattan, 1983). Warm distilled water was used to prepare an aqueous extract of dry leaves, which was mixed with $0.2 \mathrm{ml}$ of potassium triiodide solution and $0.25 \mathrm{ml}$ of $2 \mathrm{~N} \mathrm{HCl}$. After keeping this solution in an ice bath for $90 \mathrm{~min}, 20 \mathrm{ml}$ of dichloromethane and $2 \mathrm{ml}$ of water were added for the extraction of GB. The optical density of the organic phase was determined at $365 \mathrm{~nm}$, and the GB concentrations were measured on a fresh weight basis.

\section{Pigment Contents}

A known spectrophotometric-based method was followed to measure chlorophyll a (chl a), chlorophyll b (chl b), total chlorophyll (total chl), and carotenoids in leaf samples (Arnon, 1949; Peters and Noble, 2014). The pigments were extracted in $85 \%$ acetone and centrifuged at $4,000 \mathrm{rpm}$ for $15 \mathrm{~min}$; subsequently, the supernatant was used for the absorbance of the recorded values at 645,663 , and $480 \mathrm{~nm}$. Afterward, the pigment contents were calculated as follows:

$$
\begin{aligned}
& \text { Chl a }(\mathrm{mg} / \mathrm{g} \mathrm{FW}) \\
& \quad=\left[12.7\left(O D_{663}\right)-2.69\left(O D_{645}\right) \times V / 1,000 \times W\right] \\
& \text { Chl b }(\mathrm{mg} / \mathrm{g} \mathrm{FW}) \\
& \quad=\left[22.9\left(O D_{645}\right)-4.68\left(O D_{663}\right) \times V / 1,000 \times W\right] \\
& \text { Carotenoids }(\mathrm{mg} / \mathrm{g} \mathrm{FW})=\left[A_{\mathrm{car}} / \mathrm{EM}\right] \times 1,000 A_{\mathrm{car}} \\
& \quad=O D_{480}+0.114\left(O D_{663}\right)-0.638\left(O D_{645}\right)
\end{aligned}
$$

Where, OD represents optical density, $V$ is the volume of the sample, $W$ is the weight of fresh tissue taken for extraction, and $\mathrm{EM}$ is 2,500 .

\section{Yield Attributes}

The mature wheat plants were used to calculate the plant biomass, 100 -grain weight yield, and the grain yield per plant under stress and non-stress conditions.

\section{Statistical Analyses}

Finally, significance of the data was tested using variance and Tukey's (honestly significant difference, HSD) test at $p<0.05$ and, where applicable, at $p<0.01$. Thus, the mean $\pm \mathrm{SD}$ values are presented in graphs. 


\section{RESULTS}

The SS-treated and non-treated wheat seeds were allowed to germinate in pots under normal and mild drought stress conditions. Later, the flag leaf samples of 98-day mature plants were used for biochemical, physiological, and yield responses and compared with the control under stress and nonstress conditions.

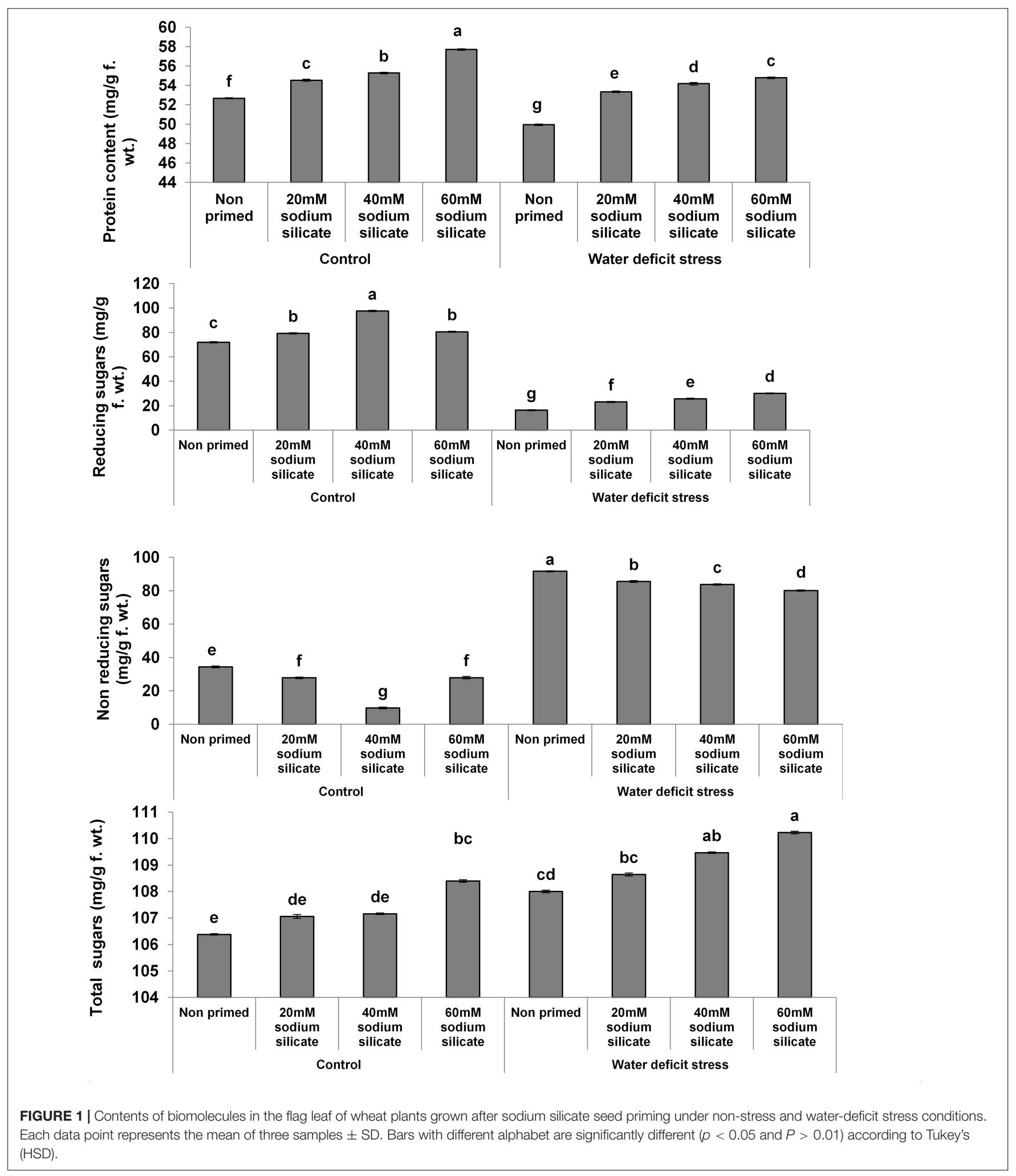




\section{Biochemical Parameters}

The protein contents increased significantly with increasing concentrations of the priming agent under normal as well as stress conditions compared to the control (Figure 1). There was a significant increase in reducing sugars with increasing concentrations of the applied sodium silicate priming solution under both conditions. However, the increasing effect was more pronounced in the flag leaves of plants originated from prime seeds under normal conditions. Interestingly, an entirely opposite effect was observed in the case of non-reducing sugars. The
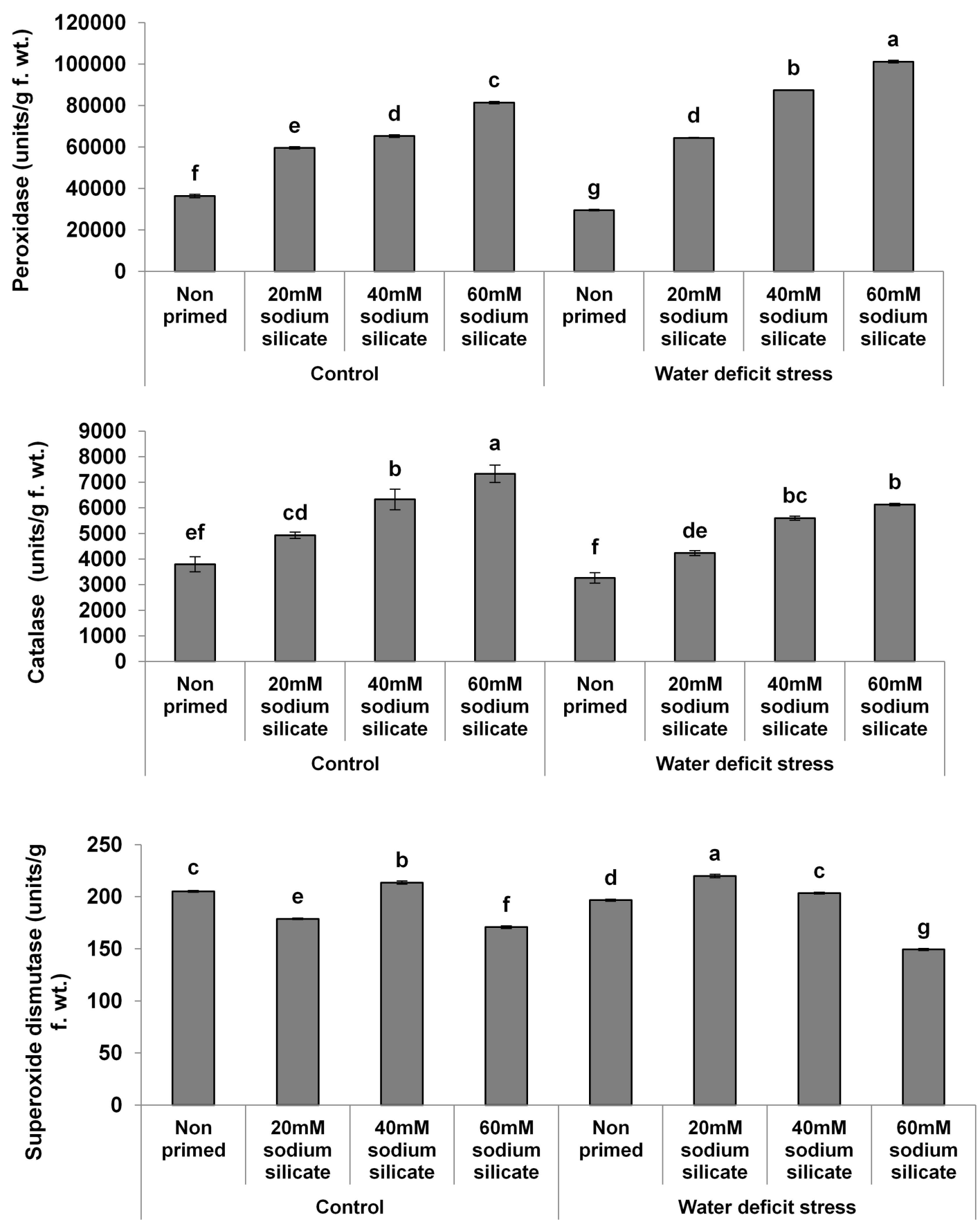

FIGURE 2 | Antioxidant enzyme activities in the flag leaf of wheat plants grown after sodium silicate seed priming under non-stress and water-deficit stress conditions. Each data point represents the mean of three samples $\pm \mathrm{SD}$. Bars with different alphabet are significantly different $(p<0.05$ and $P>0.01)$ according to Tukey's (HSD). 
total sugars increased with increasing concentrations of the priming agent under drought, while under normal conditions, only priming with $60 \mathrm{mM}$ SS treatment induced a significant increase in total sugars.

In the case of the antioxidant enzymes, both POD and CAT activities were upregulated significantly with increasing priming concentrations under both conditions. However, a more pronounced effect was observed in POD and CAT under the mild drought and normal conditions, respectively. Priming with 20 and $40 \mathrm{mM}$ SS induced a significant increase in SOD activity under drought. Under normal conditions, only $40 \mathrm{mM}$ SS treatment caused a significant increase in SOD. The maximum upregulation of SOD was observed as a result of priming with 20 mM SS under stress (Figure 2).

The MDA contents exhibited a significant decreasing trend with increasing priming concentrations. The maximum MDA
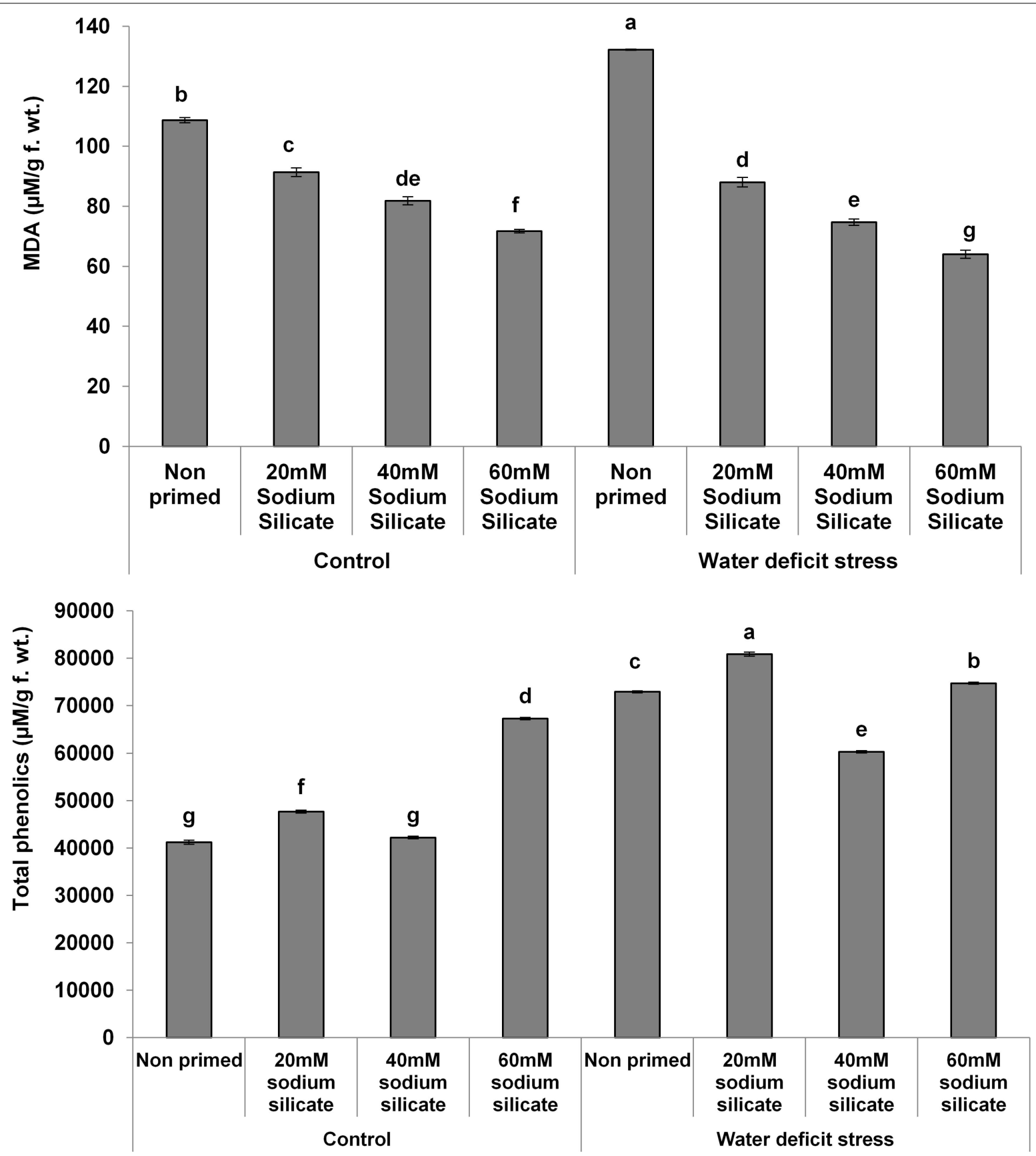

FIGURE 3 | Malondialdehyde (MDA) contents and total phenolics in the flag leaf of wheat plants grown after sodium silicate seed priming under non-stress and water-deficit stress conditions. Each data point represents the mean of three samples $\pm \mathrm{SD}$. Bars with different alphabet are significantly different $(p<0.05$ and $P>0.01$ ) according to Tukey's (HSD). 
was observed in the flag leaves of plants originated from nonprimed seeds grown under drought. Treatment with $40 \mathrm{mM} \mathrm{SS}$ induced a significant decrease, while the other treatments caused an increment in the non-enzymatic antioxidant, the TPC, under both conditions compared to the control (Figure 3). In the case of the hydrolytic enzymes, the protease and $\alpha$-amylase activities
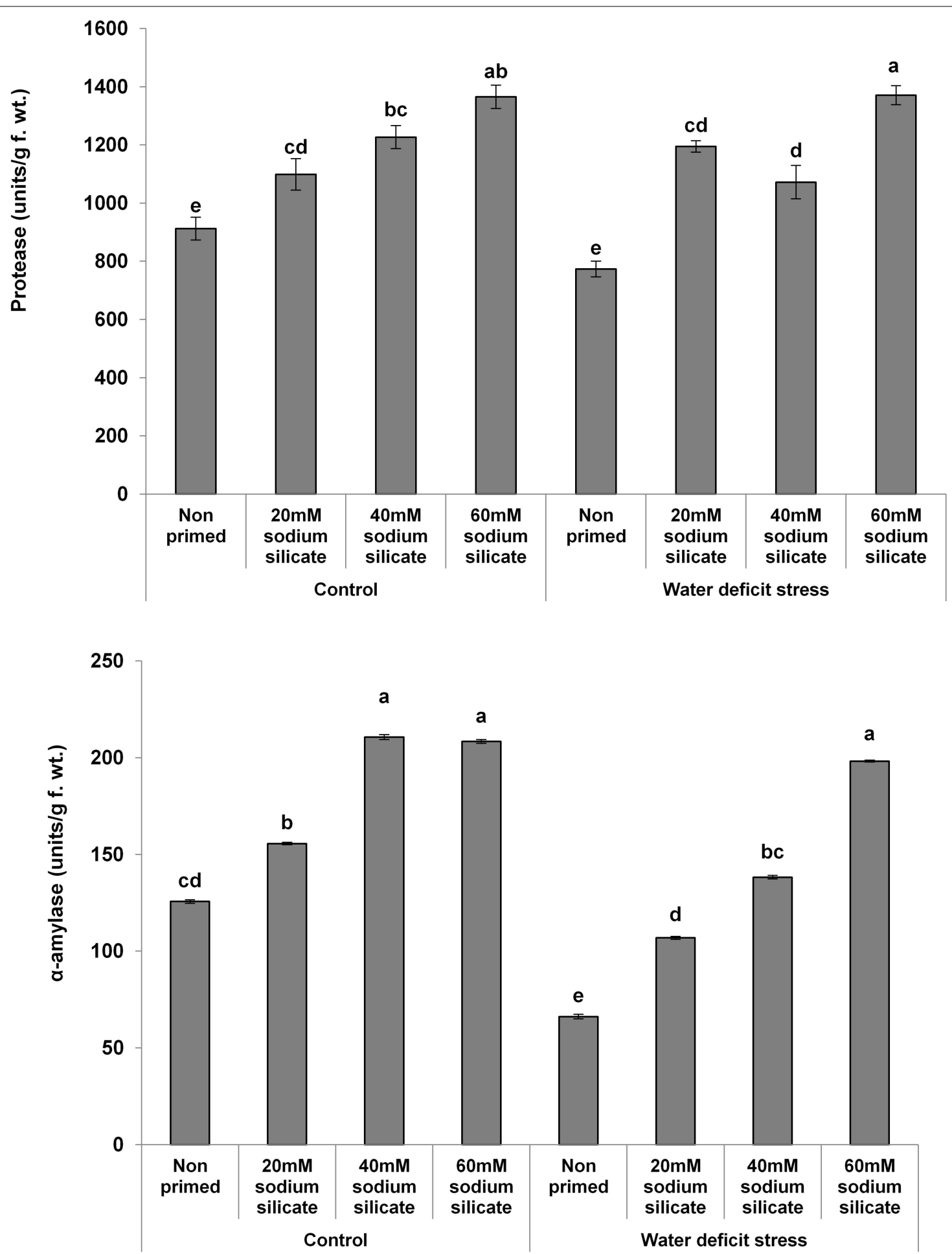

FIGURE 4 | Hydrolytic enzyme activities in the flag leaf of wheat plants grown after sodium silicate seed priming under non-stress and water-deficit stress conditions. Each data point represents the mean of three samples \pm SD. Bars with different alphabet are significantly different $(p<0.05$ and $P>0.01)$ according to Tukey's (HSD). 
were significantly upregulated due to the priming treatments under normal as well as stress conditions (Figure 4).

The proline contents decreased significantly and linearly with increasing SS priming concentrations, while a significantly linear increase was observed in GB under both conditions (Figure 5).

Priming with $40 \mathrm{mM}$ SS only caused a significant increase in chl a under normal conditions. The priming treatments induced a significant decrease in chl $\mathrm{b}$ and total chl under normal conditions. Under drought, priming with 20 and $60 \mathrm{mM}$ SS caused a significant increase in chl a and chl b, respectively. Priming with $60 \mathrm{mM}$ SS also increased the total chl significantly under stress. A significant increase in total carotenoids was observed as a result of priming with 20 and $40 \mathrm{mM}$ SS under normal conditions. Meanwhile, priming with $60 \mathrm{mM}$ induced a significant increase in total carotenoids under stress (Table 1).

\section{Physiological Parameters}

There was a significant and linear decrease in the water potential of flag leaves with increasing SS priming concentrations under both conditions. The osmotic potential exhibited a similar trend under stress. However, a significant increasing effect was induced by $60 \mathrm{mM}$ treatment under normal conditions. A significant increase in turgor potential was observed with increasing priming concentrations under both conditions (Table 2). CMS increased significantly with increasing SS priming concentrations (Figure 6).

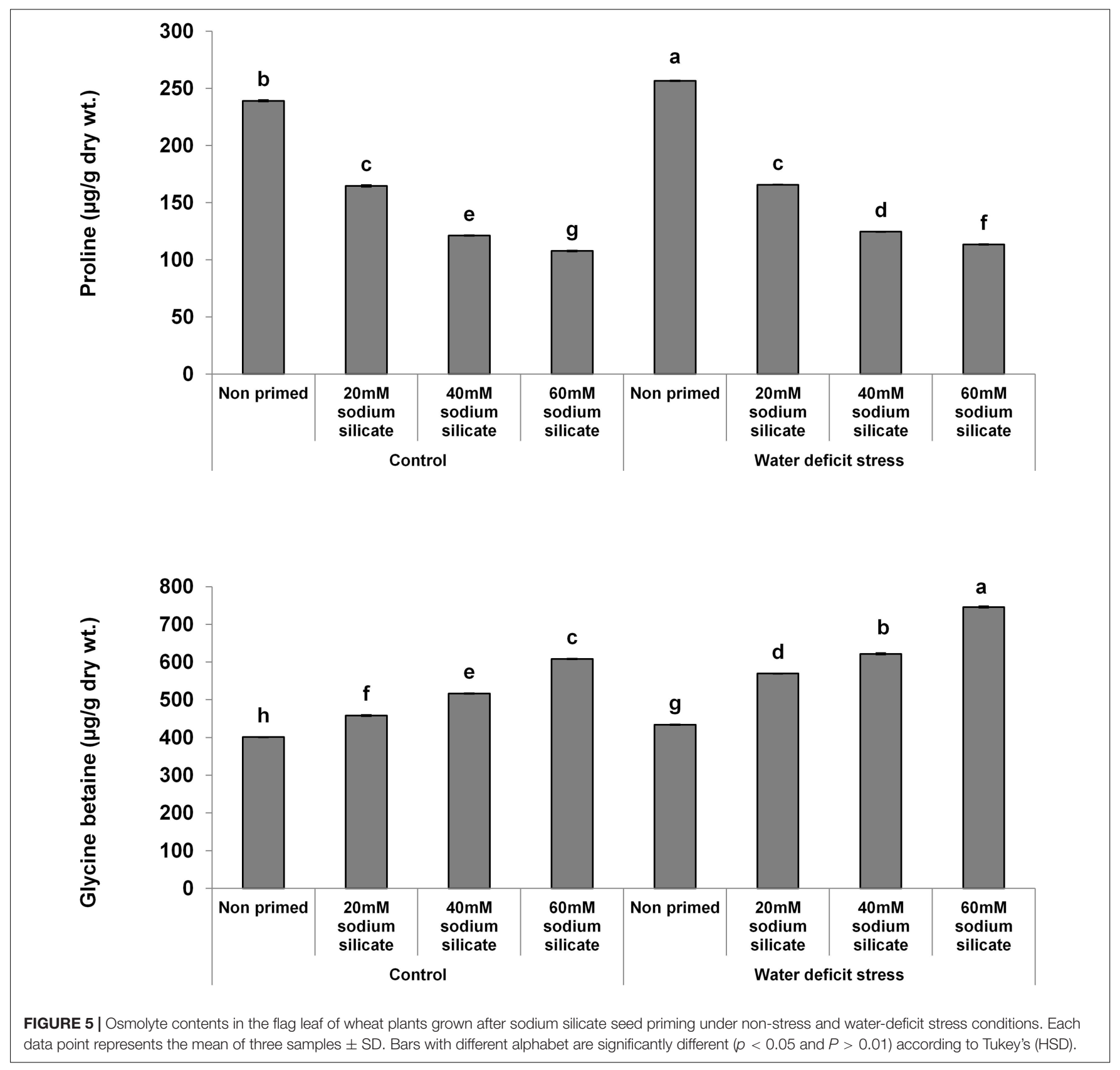




\section{Yield Attributes}

The yield of plants increased significantly with priming treatments under both conditions; however, the effect was more pronounced under stress-free conditions. A significant increase in 100-grain weight was observed only as a result of priming with $20 \mathrm{mM}$ SS under normal and stress conditions, while the other treatments were unable to induce any perceptible change in it. The priming treatments induced a significant increase in plant biomass under both conditions (Table 2).

\section{DISCUSSION}

Applications of SS as a wheat seed priming agent induced a significant increase in TSP in the flag leaves of plants under both conditions. Proteins provide energy and amino acids to germinating seeds and developing seedlings and execute a number of physiological and biochemical processes in plants, being vital enzymes in various subcellular metabolic and signaling pathways. Drought stress induces severe negative impacts on such pathways due to their high dependence on water availability (Ali and Elozeiri, 2017). As a stressmitigating strategy, plants produce drought-responsive proteins for biochemical readjustments to counterbalance the deleterious impacts and provision of resistance against stress (Al-Jebory, 2012). Silicon applications are known to enhance the expressions of drought-related proteins in rice plants under drought (Khattab et al., 2014). Accordingly, in our study, the Siinduced marked increment in TSP has been considered as a mechanistic response to water-deficit conditions. Hence, the significant improvement of the TSP content with increasing SS concentrations suggested the facilitating role of $\mathrm{Si}$ in protein synthesis under normal as well as stress conditions. The produced proteins could have assisted in the regulation of metabolic pathways and provided energy and nutrients for the induction of stress tolerance.

There were significant increases in the reducing and total sugars with increasing SS concentrations under stress and stressfree conditions. Plants increase their sugar content as a part of their stress-insulating mechanism because they could provide energy for metabolic processes and assist in the regulation of stress responses. Sugars do act as osmoprotectants and provide membrane stability, especially under water-deficit conditions (O'Hara et al., 2013; Poonam et al., 2016). Maize plants produced from Si-primed seeds were reported to show higher contents of soluble sugars under alkaline and water-deficit stress (Abdel Latef and Tran, 2016; Parveen et al., 2019). Hence, a Si-mediated increase in the reducing and total sugars has been considered as a positive factor for drought tolerance in this study. However, SS priming induced a significant decrease in non-reducing sugars, which suggested their lesser requirements in water-deficit management in this study.

In our case, the Si priming treatments significantly increased the POD and CAT activities in the flag leaves of wheat plants under normal and stress conditions. Priming with 20 and $40 \mathrm{mM}$ SS caused a significant increase in SOD activity under stress and normal conditions, respectively, while all the other 


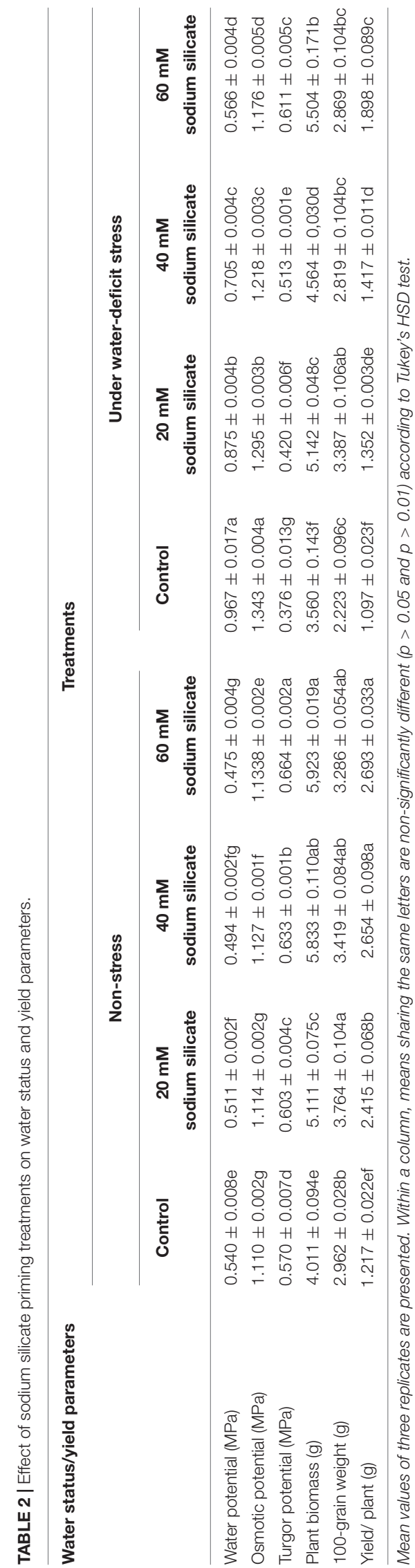

priming treatments induced a significant decrease in SOD under both conditions. In general, plants utilize non-enzymatic and enzymatic antioxidants for real-time detoxification of stressinduced reactive oxygen species (ROS). Therefore, upregulated antioxidant enzymes have been considered as a major stressresponsive strategy for counterbalancing excessive ROS (Sofo et al., 2015). The exogenous as well as priming applications of Si have been known to boost antioxidant enzymes in latesown wheat and maize plants under drought (Sattar et al., 2017; Parveen et al., 2019). Thus, in our case, the elevated activities of the antioxidant enzymes represented an increased antioxidant potential for the provision of water-deficit tolerance in wheat plants.

The overexpression of the antioxidant enzymes along with the readjustment of biomolecules might have mitigated the negative impacts of water-deficit and helped to detoxify the excessive generation of ROS. It has been signified by the significant reduction of MDA contents with increasing priming concentrations prominently under mild water-deficit conditions. Under both conditions, two priming treatments induced a significant increase in TPC, a non-enzymatic antioxidant. The elevated antioxidant potential with reduced MDA contents suggested acclimation to water deficit in wheat plants induced as priming memory in primed seeds.

In our study, the activities of both hydrolytic (protease and $\alpha$-amylase) enzymes increased significantly and almost linearly with increasing concentrations of SS under both conditions. Usually, plants show an upregulation of hydrolytic enzymes as a mechanistic approach for the mitigation of abiotic stresses including water deficit (Wang et al., 2016). They re-mobilize stored proteins and soluble sugars for the regulation of various metabolic and physiological functions vital for seed germination, seedling development, and plant growth (Adda et al., 2014; Martinez et al., 2019). In this perspective, the upregulation of the hydrolytic enzymes has been considered as a positive factor to elicit water-deficit tolerance in wheat plants.

Proline accumulation appears as one of the major stresscombating strategies in plants against a number of abiotic stresses, including water-deficit conditions. It helps the plants in osmotic readjustments for the development of water-deficit resistance. Further, it has been suggested as the biomarker of osmotic stress injury (Heuer, 2010; Chun et al., 2018). In our case, the proline contents were decreased significantly in the flag leaf of wheat plants with increasing priming concentrations compared to the control under both conditions. Accordingly, it represented that SS priming provided water-deficit acclimation in wheat plants, thus reducing the chances of osmotic injury and the requirement of proline. Glycine betaine is also produced in plants as an adaptive mechanism to counter abiotic stresses, including drought or water-deficit conditions. It is a known osmolyte that helps in stress-related osmotic readjustments for buffering of the redox potential, membrane stability, and higher ROS scavenging capacity. It interacts with the hydrophobic and hydrophilic domains of protein complexes and membranes, protects them from ROS, and maintains their structural and functional integrity. Thus, it offers counteracting mechanisms to settle the stress-related metabolic dysfunctions, ensuring 


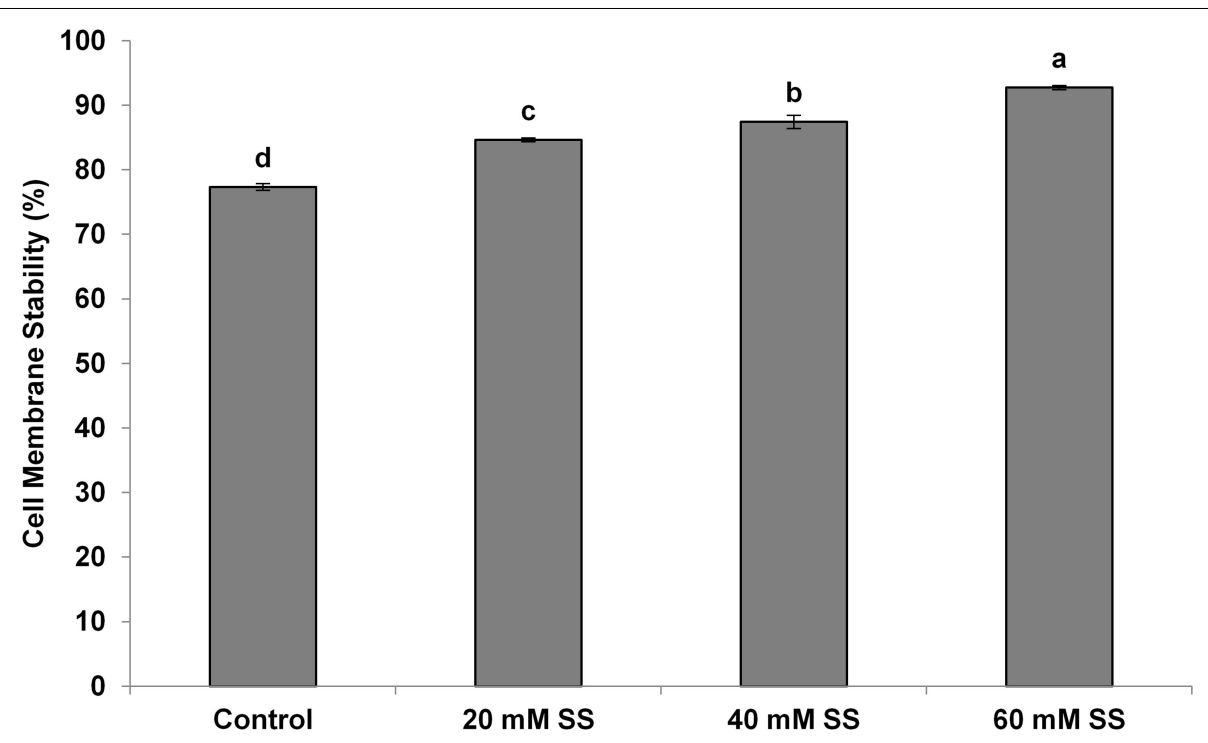

FIGURE 6 | Effect of sodium silicate seed priming on cell membrane stability. Each data point represents the mean of three samples \pm SD. Bars with different alphabet are significantly different $(p<0.05$ and $P>0.01)$ according to Tukey's (HSD).

improved growth and survival of plants (Xu et al., 2018; Annunziata et al., 2019). Silicon applications have regulated the osmolytes as a mechanistic approach to induce drought tolerance in different species of plants (Yang et al., 2017; Hasanuzzaman et al., 2018). In our case, there was a significant and linear increase in GB with increasing SS priming concentrations compared to the control under water-deficit and normal conditions. Therefore, the SS-mediated increase of GB in flag leaves has been suggested as a positive factor that elicits water-deficit tolerance in wheat plants.

Water-deficit conditions generally induce negative impacts on the chlorophyll content, resulting in a reduced photosynthetic activity (Chen et al., 2016; Hussain et al., 2019). In our case, SS priming produced significant increases in chl a, chl b, and total chl in flag leaves, suggesting the stressmitigating role of Si under mild water-deficit conditions. Further, treatment with $60 \mathrm{mM}$ SS caused a significant increase in total carotenoids under stress. In general, drought caused a significant reduction in carotenoid content in plants. They have been suggested as important precursors of plant hormones and accessory pigments for photosynthesis (Mibei et al., 2017). Foliar applications of $\mathrm{Si}$ also increased the photosynthetic pigments, including carotenoids, in wheat under normal and drought conditions (Maghsoudi et al., 2016). In a very recent study, silicon fertilization improved chlorophyll and carotenoids in sugarcane cultivars grown under water-deficit conditions (De Camargo et al., 2019). Thus, in our study, the silicon-mediated increase in photosynthetic pigments and carotenoids has been correlated to its stress alleviatory role for sustainable productivity.

In our case, the priming treatments resisted the negative impacts of mild water-deficit conditions and exhibited a significant increase in CMS in flag leaves. The increase in CMS has also been justified by a low MDA, a higher antioxidant potential, and higher amounts of osmolytes owing to the Si-regulated metabolic, biochemical, and signaling processes under mild water-deficit conditions. The increased CMS and the higher content of osmolytes developed osmoregulation, which significantly improved the relative water contents in flag leaves. Exogenous applications of Si have also been known to improve the CMS and water status in a variety of plants under different stress conditions (Bybordi, 2015; Maghsoudi et al., 2016; Altuntas et al., 2018).

All SS priming treatments induced biochemical alterations, consequently improving yield, plant biomass, and the 100-grain weight of wheat plants grown under mild water-deficit and normal conditions. The improvement of the yield parameters at the whole plant stage indicates the induction of priming memory in SS-primed seeds, which elicited water-deficit tolerance until the maturity of plants. Therefore, silicon-mediated priming memory in primed seeds enabled them to tolerate water deficit at the seed germination, seedling growth, and plant development stages, thus ensuring sustainable productivity with long-lasting stress acclimation.

\section{CONCLUSION}

The silicon-mediated priming effects elicited water-deficit resistance in wheat plants by upregulating the antioxidant and hydrolytic enzymes with an increased level of osmoprotectants. Further, it induced a significant reduction in proline and MDA contents, representing a lesser ROS production that resulted in enhanced cell membrane stability. The improvement in the yield parameters at the whole plant stage indicated the induction of priming-mediated biochemical alterations in SS-primed seeds that invoked water-deficit acclimation until the maturity of plants, ensuring climate-smart growth of wheat. 


\section{DATA AVAILABILITY STATEMENT}

The original contributions presented in the study are included in the article/Supplementary Material, further inquiries can be directed to the corresponding author/s.

\section{AUTHOR CONTRIBUTIONS}

ArH conducted the experiments and analysis of data, and performed the priming, growth, germination studies, and biochemical analyses. TF contributed to the data interpretation and manuscript writing. AmH supervised the priming, growth, germination studies, and biochemical analyses. MS proposed the research plan and supervised the priming, growth, germination studies, and biochemical analyses.

\section{REFERENCES}

Abdel Latef, A. A., and Tran, L.-S. P. (2016). Impacts of priming with silicon on the growth and tolerance of maize plants to alkaline stress. Front. Plant Sci. 7:243. doi: $10.3389 /$ fpls.2016.00243

Adda, A., Regagba, Z., Latigui, A., and Merah, O. (2014). Effect of salt stress on [Alpha]-amylase activity, sugars mobilization and osmotic potential of Phaseolus vulgaris L. Seeds Var.'Cocorose'and'Djadida'during germination. J. Biol. Sci. 14, 370-375. doi: 10.3923/jbs.2014.370.375

Ainsworth, E. A., and Gillespie, K. M. (2007). Estimation of total phenolic content and other oxidation substrates in plant tissues using Folin-Ciocalteu reagent. Nat. Protoc. 2:875. doi: 10.1038/nprot.2007.102

Ali, A. S., and Elozeiri, A. A. (2017). "Metabolic processes during seed germination," in Advances in Seed Biology, ed. J. C. Jimenez-Lopez (London: IntechOpen), 141.

Al-Jebory, E. I. (2012). Effect of water stress on carbohydrate metabolism during Pisum sativum seedlings growth. Euphrates J. Agric. Sci. 4, 1-12.

Altuntas, O., Dasgan, H. Y., and Akhoundnejad, Y. (2018). Silicon-induced salinity tolerance improves photosynthesis, leaf water status, membrane stability, and growth in pepper (Capsicum annuum L.). HortScience 53, 1820-1826. doi: 10.21273/hortsci13411-18

Amirjani, M., and Mahdiyeh, M. (2013). Antioxidative and biochemical responses of wheat to drought stress. J. Agric. Biol. Sci. 8, 291-301.

Annunziata, M. G., Ciarmiello, L. F., Woodrow, P., Dell'Aversana, E., and Carillo, P. (2019). Spatial and temporal profile of Glycine Betaine accumulation in plants under Abiotic stresses. Front. Plant Sci. 10:230. doi: 10.3389/fpls.2019. 00230

Aranega-Bou, P., de la O Leyva, M., Finiti, I., García-Agustín, P., and GonzálezBosch, C. (2014). Priming of plant resistance by natural compounds. Hexanoic acid as a model. Front. Plant Sci. 5:488. doi: 10.3389/fpls.2014.00488

Arnon, D. I. (1949). Copper enzymes in isolated chloroplasts. Polyphenoloxidase in Beta vulgaris. Plant Physiol. 24, 1-15. doi: 10.1104/pp.24.1.1

Bano, A., Ullah, F., and Nosheen, A. (2012). Role of abscisic acid and drought stress on the activities of antioxidant enzymes in wheat. Plant Soil Environ. 58, 181-185. doi: 10.17221/210/2011-pse

Bates, L. S., Waldren, R. P., and Teare, I. (1973). Rapid determination of free proline for water-stress studies. Plant Soil 39, 205-207. doi: 10.1007/bf00018060

Bhardwaj, R. D., Kaur, L., and Srivastava, P. (2017). Comparative evaluation of different phenolic acids as priming agents for mitigating drought stress in wheat seedlings. Proc. Natl. Acad. Sci. India B Biol. Sci. 87, 1133-1142. doi: 10.1007/s40011-015-0690-y

Blum, A., and Ebercon, A. (1981). Cell membrane stability as a measure of drought and heat tolerance in wheat 1. Crop Sci. 21, 43-47. doi: 10.2135/cropscil981. 0011183x002100010013x

Bradford, M. M. (1976). A rapid and sensitive method for the quantitation of microgram quantities of protein utilizing the principle of protein-dye binding. Anal. Biochem. 72, 248-254. doi: 10.1016/0003-2697(76)90527-3
All authors contributed to the article and approved the submitted version.

\section{ACKNOWLEDGMENTS}

This article is a part of the Ph.D. thesis of the corresponding author entitled "Biochemical Aspects of Drought Tolerance Induced by Seed Priming in Wheat."

\section{SUPPLEMENTARY MATERIAL}

The Supplementary Material for this article can be found online at: https://www.frontiersin.org/articles/10.3389/fpls.2021. $625541 /$ full\#supplementary-material

Bybordi, A. (2015). Influence of exogenous application of silicon and potassium on physiological responses, yield, and yield components of salt-stressed wheat. Commun. Soil Sci. Plant Anal. 46, 109-122. doi: 10.1080/00103624.2014.956936

Chance, B., and Maehly, A. (1955). Assay of catalases and peroxidases. Methods Biochem. Anal. 1, 357-424. doi: 10.1002/9780470110171.ch14

Chen, D., Wang, S., Cao, B., Cao, D., Leng, G., Li, H., et al. (2016). Genotypic variation in growth and physiological response to drought stress and ReWatering reveals the critical role of recovery in drought adaptation in maize seedlings. Front. Plant Sci. 6:1241. doi: 10.3389/fpls.2015.01241

Chun, S. C., Paramasivan, M., and Chandrasekaran, M. (2018). Proline accumulation influenced by Osmotic stress in Arbuscular Mycorrhizal symbiotic plants. Front. Microbiol. 9:2525. doi: 10.3389/fmicb.2018.02525

De Camargo, M., Bezerra, B., Holanda, L., Oliveira, A., Vitti, A., and Silva, M. (2019). Silicon fertilization improves physiological responses in sugarcane cultivars grown under water deficit. J. Soil Sci. Plant Nutr. 19, 81-91. doi: 10.1007/s42729-019-0012-1

Drapeau, G. R. (1976). "Protease from Staphyloccus aureus," in Methods in Enzymology, Vol. 45, eds J. Abelson, M. Simon, G. Verdine, and A. Pyle (Amsterdam: Elsevier), 469-475. doi: 10.1016/s0076-6879(76)45041-3

Dubois, M., Gilles, K., Hamilton, J., Rebers, P., and Smith, F. (1951). A colorimetric method for the determination of sugars. Nature 168, 167-167.

Easwar Rao, D., and Viswanatha Chaitanya, K. (2020). Changes in the antioxidant intensities of seven different soybean (Glycine max (L.) Merr.) cultivars during drought. J. Food Biochem. 44:e13118.

Giannopolitis, C. N., and Ries, S. K. (1977). Superoxide dismutases: I. Occurrence in higher plants. Plant Physiol. 59, 309-314. doi: 10.1104/pp.59.2.309

Grieve, C., and Grattan, S. (1983). Rapid assay for determination of water soluble quaternary ammonium compounds. Plant Soil 70, 303-307. doi: 10.1007/ bf02374789

Guan, X. K., Song, L., Wang, T. C., Turner, N., and Li, F. M. (2015). Effect of drought on the gas exchange, chlorophyll fluorescence and yield of six different-era spring wheat cultivars. J. Agron. Crop Sci. 201, 253-266. doi: $10.1111 /$ jac. 12103

Guo, Q., Wang, Y., Zhang, H., Qu, G., Wang, T., Sun, Q., et al. (2017). Alleviation of adverse effects of drought stress on wheat seed germination using atmospheric dielectric barrier discharge plasma treatment. Sci. Rep. 7:16680.

Habib, N., Ali, Q., Ali, S., Javed, M. T., Haider, M. Z., Perveen, R., et al. (2020). Use of nitric oxide and hydrogen peroxide for better yield of wheat (Triticum aestivum L.) under water deficit conditions: growth, osmoregulation, and Antioxidative defense mechanism. Plants 9:285. doi: 10.3390/plants9020285

Hameed, A., Hameed, A., Farooq, T., Noreen, R., Javed, S., Batool, S., et al. (2019). Evaluation of structurally different benzimidazoles as priming agents, plant defence activators and growth enhancers in wheat. BMC Chem. 13:29. doi: 10.1186/s13065-019-0546-2

Hameed, A., and Iqbal, N. (2014). Chemo-priming with mannose, mannitol and H 2 O 2 mitigate drought stress in wheat. Cereal Res. Commun. 42, 450-462. doi: $10.1556 /$ crc.2013.0066 
Hasanuzzaman, M., Nahar, K., Anee, T., Khan, M., and Fujita, M. (2018). Siliconmediated regulation of antioxidant defense and glyoxalase systems confers drought stress tolerance in Brassica napus L. S. Afr. J. Bot. 115, 50-57. doi: 10.1016/j.sajb.2017.12.006

Heath, R. L., and Packer, L. (1968). Photoperoxidation in isolated chloroplasts: I. kinetics and stoichiometry of fatty acid peroxidation. Arch. Biochem. Biophys. 125, 189-198. doi: 10.1016/0003-9861(68)90 654-1

Heuer, B. (2010). "Role of proline in plant response to drought and salinity," in Handbook of Plant and Crop Stress, ed. M. Pessarakli (Boca Raton: CRC Press).

Hussain, H. A., Men, S., Hussain, S., Chen, Y., Ali, S., Zhang, S., et al. (2019). Interactive effects of drought and heat stresses on morpho-physiological attributes, yield, nutrient uptake and oxidative status in maize hybrids. Sci. Rep. 9:3890. doi: 10.1038/s41598-019-40362-7

Karim, M. R., Zhang, Y. Q., Zhao, R. R., Chen, X. P., Zhang, F. S., and Zou, C. Q. (2012). Alleviation of drought stress in winter wheat by late foliar application of zinc, boron, and manganese. J. Plant Nutr. Soil Sci. 175, 142-151. doi: 10.1002/jpln.201100141

Khattab, H., Emam, M., Emam, M., Helal, N., and Mohamed, M. (2014). Effect of selenium and silicon on transcription factors NAC5 and DREB2A involved in drought-responsive gene expression in rice. Biol. Plant. 58, 265-273. doi: 10.1007/s10535-014-0391-z

Li, S., Li, X., Wei, Z., and Liu, F. (2020). ABA-mediated modulation of elevated CO2 on stomatal response to drought. Curr. Opin. Plant Biol. 56, 174-180. doi: 10.1016/j.pbi.2019.12.002

Liu, B., Soundararajan, P., and Manivannan, A. (2019). Mechanisms of siliconmediated amelioration of salt stress in plants. Plants 8:307. doi: 10.3390/ plants8090307

Maghsoudi, K., Emam, Y., and Pessarakli, M. (2016). Effect of silicon on photosynthetic gas exchange, photosynthetic pigments, cell membrane stability and relative water content of different wheat cultivars under drought stress conditions. J. Plant Nutr. 39, 1001-1015. doi: 10.1080/01904167.2015.1109108

Martinez, M., Gómez-Cabellos, S., Giménez, M. J., Barro, F., Diaz, I., and DiazMendoza, M. (2019). Plant Proteases: from key enzymes in germination to allies for fighting human gluten-related disorders. Front. Plant Sci. 10:721. doi: $10.3389 /$ fpls.2019.00721

Mibei, E. K., Ambuko, J., Giovannoni, J. J., Onyango, A. N., and Owino, W. O. (2017). Carotenoid profiling of the leaves of selected African eggplant accessions subjected to drought stress. Food Sci. Nutr. 5, 113-122. doi: 10.1002/ fsn 3.370

Miller, G. L. (1959). Use of dinitrosalicylic acid reagent for determination of reducing sugar. Anal. Chem. 31, 426-428. doi: 10.1021/ac60147a030

Mohanty, S., Nayak, A. K., Swain, C. K., Dhal, B., Kumar, A., Tripathi, R., et al. (2020). Silicon enhances yield and nitrogen use efficiency of tropical low land rice. Agron. J. 112, 758-771. doi: 10.1002/agj2.20087

O'Hara, L. E., Paul, M. J., and Wingler, A. (2013). How do sugars regulate plant growth and development? New insight into the role of trehalose-6-phosphate. Mol. Plant 6, 261-274. doi: 10.1093/mp/sss120

Pang, Z., Tayyab, M., Islam, W., Tarin, M. W. K., Sarfraz, R., Naveed, H., et al. (2019). Silicon mediated improvement in tolerance of economically important crops under drought stress. Appl. Ecol. Environ. Res. 17, 6151-6170.

Parveen, A., Liu, W., Hussain, S., Asghar, J., Perveen, S., and Xiong, Y. (2019). Silicon priming regulates morpho-physiological growth and oxidative metabolism in Maize under drought stress. Plants 8:431. doi: 10.3390/ plants8100431

Peters, R. D., and Noble, S. D. (2014). Spectrographic measurement of plant pigments from 300 to $800 \mathrm{~nm}$. Remote Sens. Environ. 148, 119-123. doi: $10.1016 /$ j.rse.2014.03.020
Poonam, R. B., Handa, N., Kaur, H., Rattan, A., and Bali, S. (2016). “Sugar signalling in plants: a novel mechanism for drought stress management," in Water Stress and Crop Plants, ed. P. Ahmad (Hoboken, NJ: Wiley), 287-302. doi: 10.1002/ 9781119054450.ch19

Sattar, A., Cheema, M., Abbas, T., Sher, A., Ijaz, M., Wahid, M., et al. (2017). Physiological response of late sown wheat to exogenous application of silicon. Cereal Res. Commun. 45, 202-213. doi: 10.1556/0806.45.2017.005

Savvides, A., Ali, S., Tester, M., and Fotopoulos, V. (2016). Chemical priming of plants against multiple abiotic stresses: mission possible? Trends Plant Sci. 21, 329-340. doi: 10.1016/j.tplants.2015.11.003

Singh, V. K., Singh, R., Tripathi, S., Devi, R. S., Srivastava, P., Singh, P., et al. (2020). "Seed priming: state of the art and new perspectives in the era of climate change," in Climate Change and Soil Interactions, eds M. N. V. Prasad and M. Pietrzykowski (Amsterdam: Elsevier), 143-170. doi: 10.1016/b978-0-12818032-7.00006-0

Sofo, A., Scopa, A., Nuzzaci, M., and Vitti, A. (2015). Ascorbate peroxidase and catalase activities and their genetic regulation in plants subjected to drought and salinity stresses. Int. J. Mol. Sci. 16, 13561-13578. doi: 10.3390/ijms160613561

Teh, S. Y., and Koh, H. L. (2016). Climate change and soil salinization: impact on agriculture, water and food security. Int. J. Agric. For. Plant. 2, 1-9. doi: 10.1002/9781119180661.ch1

Varavinit, S., Chaokasem, N., and Shobsngob, S. (2002). Immobilization of a thermostable alpha-amylase. Sci. Asia 28, 247-251.

Wang, J. Y., Turner, N. C., Liu, Y. X., Siddique, K. H., and Xiong, Y. C. (2017). Effects of drought stress on morphological, physiological and biochemical characteristics of wheat species differing in ploidy level. Funct. Plant Biol. 44, 219-234. doi: 10.1071/fp16082

Wang, X., Cai, X., Xu, C., Wang, Q., and Dai, S. (2016). Drought-responsive mechanisms in plant leaves revealed by proteomics. Int. J. Mol. Sci. 17:1706 doi: 10.3390/ijms17101706

Wang, Z., Li, G., Sun, H., Ma, L., Guo, Y., Zhao, Z., et al. (2018). Effects of drought stress on photosynthesis and photosynthetic electron transport chain in young apple tree leaves. Biol. Open 7:bio035279. doi: 10.1242/bio.035279

Wojtyla, Ł, Lechowska, K., Kubala, S., and Garnczarska, M. (2016). Molecular processes induced in primed seeds-increasing the potential to stabilize crop yields under drought conditions. J. Plant Physiol. 203, 116-126. doi: 10.1016/j. jplph.2016.04.008

Xu, Z., Sun, M., Jiang, X., Sun, H., Dang, X., Cong, H., et al. (2018). Glycinebetaine biosynthesis in response to osmotic stress depends on Jasmonate signaling in watermelon suspension cells. Front. Plant Sci. 9:1469. doi: 10.3389/fpls.2018. 01469

Yang, L., Han, Y., Li, P., Li, F., Ali, S., and Hou, M. (2017). Silicon amendment is involved in the induction of plant defense responses to a phloem feeder. Sci. Rep. 7:4232.

Zlatev, Z. (2009). Drought-induced changes in chlorophyll fluorescence of young wheat plants. Biotechnol. Biotechnol. Equip. 23, 438-441. doi: 10.1080/ 13102818.2009.10818458

Conflict of Interest: The authors declare that the research was conducted in the absence of any commercial or financial relationships that could be construed as a potential conflict of interest.

Copyright (c) 2021 Hameed, Farooq, Hameed and Sheikh. This is an open-access article distributed under the terms of the Creative Commons Attribution License (CC BY). The use, distribution or reproduction in other forums is permitted, provided the original author(s) and the copyright owner(s) are credited and that the original publication in this journal is cited, in accordance with accepted academic practice. No use, distribution or reproduction is permitted which does not comply with these terms. 